\title{
Securizing care: Networks, Immediacy and Independence in a Home Telecare Service
}

\section{Asegurar el cuidado: Redes, Inmediatez y Autonomía en un Servicio de Teleasistencia Domiciliaria}

\author{
Daniel López \\ Universitat Oberta de Catalunya \\ dlopezgo@uoc.edu
}

\begin{abstract}
Resumen
Esta tesis es un estudio etnográfico sobre un servicio de teleasistencia domiciliaria en el que se analiza cómo se organiza el cuidado a distancia e inmediato ante cualquier eventualidad, cómo se corporeiza y práctica la autonomía a través del uso de este servicio, y cómo el hogar y su forma de habitarlo se transforma con el uso de la teleasistencia. Estas tres preguntas tienen como objetivo final dilucidar qué desinstitucionalización se abre con la TAD. Concretamente, la tesis que sostiene el trabajo es que la desinstitucionalización puede interpretarse, a la luz de los resultado de la etnografía, como el paso de un disciplinamiento del cuidado a un aseguramiento del cuidado.
\end{abstract}

\begin{abstract}
This thesis comes from an ethnography conducted in a Home Telecare Service and it is mainly concerned with how remote and immediate care is organized, how independence is embodied and enacted by the use, misuse or non use of the service and how the users' homes and the practices of dwelling are shaped by the incorporation of the service. The main aim of these empirical questions is to explore what kind of deinstitutionalization process is being configured through telecare. Specifically, the main statement I would like to put forward is that deinstitutionalization can be understood, according to the telecare case study, as the shift from a disciplining care regime to a securitizing care regime.
\end{abstract}

Palabras clave: Cuidado; Seguridad; Teoría del actor- Keywords: Care; Security; Actor-network theory; STS; red; Estudios ociales de la ciencia y la tecnología; Foucault; Telecare; Space

Foucault; Teleasistencia; Espacio

The origin of this thesis is the brochure that I came across in 2000 in an office of the Provincial Council on Barcelona's Londres Street when I was working on a project to promote a network of associations for the elderly. It was a pamphlet on home telecare (HTC) provided by the Red Cross, and it condensed both the subject of this research and many of the questions that I ask in this study, from the most trivial to the most profound. In fact, I believe that the study that I have been conducting over these years has been nothing other than an attempt to describe each of the elements and explain the fact that these elements were related. How can a button worn around the neck offer company and safety? How can pressing a button become an easy or difficult action? Why does safety imply immediacy? How does a technological device enable someone to remain at home? Why is it that maintaining one's habits constitutes a kind of autonomy? These are the questions guiding this thesis which I have examined individually in each of the publications presented here. 
Obviously, one does not set out to write a thesis on this device solely on a whim. As with all mythical origins, coming across the HTC brochure, albeit by chance, was laden with meaning. When I embarked on the doctorate I had a chance to work alongside other researchers from Loughborough in a joint project entitled "Virtualization of Institutions". The goal of this project was to pool different studies on the role of the new technologies in the transformation of institutions. However, the approach in this project purposefully avoided technological determinism and the hyperbolic discourses on the new technologies. The challenge was precisely to study virtualisation as a general process not directly related to the digital technologies, but one that simultaneously had a specificity in contemporary organisations. To accomplish this, we constructed a theoretical framework based on the notions of virtuality set forth by Deleuze, Bergson, Serres and Lévy and in the Actor-Network Theory. It was therefore on the basis of these empirical and theoretical concerns that the finding of the brochure on home telecare aroused enough interest in me to make it the subject of this doctoral thesis. Therefore, the choice was not random but totally opportunistic. Finding the brochure also watered the germ of an intuition: home telecare might give us clues as to how care is spatialised in a deinstitutionalised setting, what its effects are and what role the different information technologies play in it. At first glance, in the form of HTC itself there seemed to materialise a shift from the location of care in a specific site to its configuration in a network in which, with the aid of ICTs, different actors (family members, police, volunteers, and ambulances) located in different spatial and temporal points had to be coordinated.

Therefore, both the initial goal of this thesis and its end result are a kind of critical diagnosis of this deinstitutionalisation. However, to undertake this diagnosis I did not set out to take HTC as an exemplary case of deinstitutionalisation, as if it were a specific representation of a more sweeping transformation. That approach would have meant turning HTC into a simple sounding board for discussions on deinstitutionalisation. I have tried not to take $\mathrm{HTC}$ as a representation of deinstitutionalisation. In fact, my aim was to examine home telecare and thus explore the processes and problems defining it, and based on that, examine deinstitutionalisation. The goal, therefore, is to analyse how deinstitutionalisation is carried out and defined in the home telecare service, taking this mechanism as a specific example that should be given priority.

In this sense, I would describe this thesis as a metonymic essay. Through the description of a series of relations among different actors, practices, objects and discourses that give shape to HTC, I will try to sketch the face of the society that is constructed by this mechanism.

\section{Methodology}

To do this I conducted an ethnographic study in the HTC Service offered by the Catalonian Red Cross between November 2003 and July 2004. It combined participant observation (in this case not undercover), documentary analysis and interviews in three different settings:

a) The Home Telecare Service (HTCS) office of the Red Cross, where the management and administration of the service were located; the user care service, which is in charge of processing the inscriptions and ex-inscriptions and possible complaints; and the technical service, which is charged with repairing and checking damaged equipment and pilot testing new equipment. At the time of the study, this office had its own location separate from the alarm headquarters, but currently they are housed together. 
b) Alarm headquarters, where the telephone operators of the service deal with the calls and alarms.

c) Installers and volunteers, who go to the users' homes and are in direct contact with them.

In each of these settings, I conducted semi-structured interviews with key people and diverse observations through a variety of key informants. In the case of the HTCS office, the key people were the Head of Service Quality and one of the technicians who repaired the devices. At the alarm headquarters, the main key informants were a service operator on the morning shift and an alarm headquarters coordinator. For the installers, the key informant was the technicians in charge of training the new installers.

In each of these settings, I paid special attention to the practices and explanations that the different actors provided me with, to the different technologies that were used and especially to the paperwork, which consisted of recordkeeping practices. In this sense, three kinds of documents were shown to be indispensable: the forms used for paper and digital communication and filing, the service quality handbook and the protocols and action guides.

With regard to the interviews, I held individual in-depth interviews with key people in the service, as well as discussion groups.

- Five individual interviews with workers in the home telecare service who had different roles and degrees of responsibility: the head of the HTC project, the manager of the alarm headquarters, the shift coordinator of telephone operators, an alarm headquarters technician and the head of home telecare service quality.

- Three individual interviews with users of different profiles: a user without either a worker or volunteer visit; a user without a worker but with a volunteer; and a user with both worker and volunteer visits.

- Three discussion groups with people directly involved in caring for the users (two different shifts of telephone operators, one extensive group of technicians and volunteers from different local offices).

- Two extensive discussion groups with volunteers: one with family members and another with users. In this case, the selection of participants was complicated because the only people who could attend were those who could move about easily because they could physically attend, because they lived nearby, or because they had someone who could accompany them. In addition, for both family members and users, the participants were people with some kind of link with the Red Cross or who had been using the service for a long time and were very happy with it, as the Red Cross selected them directly.

\section{The analytical tools}

The ethnographic work is accompanied by equally important theoretical work. Conducting a metonymic study like the one I have tried to do has required the use of a variety of conceptual tools, specifically STS, and in particular the Actor-Network Theory, and the work of Foucault. In fact, both theoretical frameworks coincided on the approach of this study. In both cases, they stress the importance of approaching any 
object as an individual case and not as an instance of representation of a higher order, and dealing with any generalisation as a concrete totalisation that emerges from the connection of this singularity with others. Furthermore, both cases stress the importance of considering the subjects being studied, whether they be institutions, domestic spaces, technologies, care-giving practices or bodies, centrally, based on their constitutional heterogeneity.

This principle of heterogeneity and agnosticism towards the ontology of the subjects we are studying has been fundamental in my work for thinking about the care-giving space, for example, from the organisation of the service to the role played by the home in remote care and the autonomy of the users of the remote care service.

For this reason, the main mission was to track the actors agnostically, without predefining their nature. As Latour suggests, tracking the actors necessarily means paying attention to everything that acts, that produces an effect, an utterable difference, regardless of whether it is a human or non-human element. This includes everything from the action protocols used by the telephone operators in the service, which enable them to know whether there is a health emergency, to the database where the coded calls are recorded, and including the HTC button that users must wear around their neck. All of these elements are articulated and open up multiple spaces, share multiple bodies and forms of autonomy and make diverse care-giving and healthcare practices possible. And therefore, they become the main focal point of the fieldwork.

On the other hand, studying the home telecare from this standpoint meant establishing a meticulous relationship with what we were studying: being sensitive to the mechanisms through which something is absent or present, purified or hybridised, connected or disconnected, localised or globalised.

In this sense, the ethnographic study's complicity with the ANT and Foucault's thinking not only has led us to shift from taking home telecare as a case for studying deinstitutionalisation to taking deinstitutionalisation as a defined dimension of a mode specified by HTC, but it has also led the very definition of HTC to become a problem to be resolved. Remote care has gradually ceased to be a system of distance-based care characteristic of a deinstitutionalised setting to become a complex multi-faceted multiplicity. The thesis, in consequence, has become an ongoing exercise that seeks to unravel this multiplicity. For this reason, although the thesis examines remote care, we can find a whole host of topics.

First, it examines different artefacts and technologies. A terminal with a button is installed in a home, and with it users can call the alarm headquarters and ask for help just by pressing a button. The alarm headquarters is full of computers with operators that field calls 24 hours a day, 365 days a year, thanks to a database with information on each user.

It also examines a series of practices: immediate response, providing company, assessing the specific risks and needs in each case and calling ambulances, doctors, family members, fire service, etc. All of these practices and the way they are organised and related to each other are also the subject of this thesis.

So are the actors involved: users, caregivers, telephone operators, technicians, volunteers, coordinators, doctors. The subject of this thesis is, then, an organisation which is simultaneously a service that offers certain goods: "safety" because it offers a remote response to any emergency or problem; "company" because it is concerned about the users and with them when they need it; "remote care" because it is 
aware of the risks and needs of each user; and "autonomy" because it enables elderly people to continue living in their home and retain their habitual lifestyles.

Therefore, we might also think that this thesis is not just about technological artefacts but also on society as a whole: an aged society in which most of the spending on healthcare is allocated to long-term care needs; a society in which the nuclear family has become a patchwork family; a society in which caregiving has become an optional activity and work and consumption occupy most of the time and space; a deinstitutionalised society in which the major residential (or enclosed) centres have given way to a myriad of resources in the community which act in coordination to solve people's needs; a society in which the home has become a place of consumption, care, work, etc. The thesis also, therefore, covers all of these things.

\section{Outline}

This thematic plurality also explains the form of the thesis. I decided to write a thesis using a compendium of publications because this enables me to focus on the particularities of the fieldwork and its specific problems. On the basis of them alone I have returned to the discussion of deinstitutionalisation. In this sense, the organisation of the thesis also fits within this logic. First, we shall focus on an analysis of HTC as a device, and then later I will connect the particular areas studied with broader discussions.

Therefore, the first section includes the compendium of publications itself, and its purpose is to unpack home telecare as a multiplicity. This section is the analytical part of the ethnographic study and is organised around three problems: the spatialisation of care and of immediacy, the definition of the remotely cared for home and the ways of setting it up, and the embodiment of autonomy through home telecare.

The first focal point of analysis is the topology of the service, i.e., the different spatialisations that shape it and that organise the care that the service provides. First, we show in a publication called Approach to the Topology of the Actor-Network Theory. Analysis of Spatialities of a Remote Home Care Service (Publication 1, p. 68), how the service is shaped based on different spatialisations. Later, in On inscriptions and ex-inscriptions. The production of immediacy in a Home Telecare Service (Publication 2, p. 94), we shall analyse how each of them takes part in a different definition of what immediate care is.

The second focal point of analysis is the relationship between remote care and the home-based care. In Dwelling the Telecare Home: Place, Location and Habitality (Publication 3, p. 108), we analyse how users set up remote care in their homes and how its use takes part in redefining the home and how to be in it.

The third focal point of interest involves the autonomous practices that arise from the use of home telecare by users. In Embodying Autonomy in a Home Telecare Service (publication 4, p. 124), we analyse how the use of the system involves the embodiment of two forms of autonomy: one focused on risk and another on vigour.

\section{Conclusions}

After the publications, I have striven to establish a dialogue between the aspects of telecare analysed in them, fundamentally based on the Actor-Network Theory and Foucaultian literature on governability and 
the so-called surveillance studies. Therefore, in the second section we connect the publications to a critical reflection on deinstitutionalisation and community care. The intention is to trace a map of intelligibility that connects the contributions of each publication and that enables us to shed light on the differences and continuities between HTC and the traditional care-giving institutions. By drawing up and discussion different diagrams that sum up the meaning of the specificities of HTC, such as the notion of extitution or panopticism, I have borrowed from Foucault's genealogy of power to show how the analysis we have carried out of this remote care system defines community care not as a shift in the place of care such as the institution or the home to open, reticular spaces of care but as a shift from a disciplinary regime to a regime based on security.

Deinstitutionalisation and community care-giving services have been interpreted in accordance with a shift in the mechanisms of power which go

- from the body to information

- $\quad$ from places to networks

- from individuals to dividuals

This shift has been interpreted by some people as the emergence of a post-disciplinary order; however, as we discuss in this thesis, it entails instead the virtualisation and extension of disciplines throughout society, or in Foucaultian terms, the shift from discipline-blockage to discipline-mechanisms; in other words, the emergence of panopticism as a logic of power that is characteristic of modern societies. This logic explains many of the features of HTC and also of community care. However, in HTC we can also see a different logic of power emerge: that of security.

In the different publications, the importance of inclusive management of the event as a mechanism for producing order has shown itself to be increasingly essential in defining HTC. This management is what Foucault defines as security and enables a social diagram to be drawn that connects this device with others and makes it contemporary.

Therefore, in addition to shedding light on the different problems analysed in the publications, the notion of security enables us to resituate the discussion on deinstitutionalisation and go beyond the dystopian and somewhat hyperbolic interpretations of the proliferation of surveillance devices. What is important is not the dismantlement of the institutions of enclosure and the rise of community care in the home per se, nor is it the development and implementation of increasingly specific remote care devices. Instead, what is important is that all of these spaces, regardless of whether or not there is enclosure, or whether or not ICTs are involved or not, are organised as secure spaces of safety because the elements shaping them (bodies, technologies, objects, etc.) are set up with a view to possible events. Setting spaces up according to risks is characteristic of security, whether we are talking about centres of enclosure, home care or domotic houses designed for the elderly. And this is something that can be seen very clearly in HTC.

It is therefore the question of security that connects and gives meaning to the set of publications presented. Security is the problem that structures the social-technical order of HTC. Immediate care, the inclusion of autonomy, ageing at home and, finally, care make sense when they are based on and designed for security. 
Therefore, immediacy enables the users to feel safe at home, as they can be sure that should any problem arise they will receive specific, immediate attention. Security is what gives meaning to the conflict that arises between a practice of autonomy viewed based on vigour and resistance and a practice based on self-surveillance and the calculation of possibilities for action. Security is also the dimension that furnishes intelligibility to the shift from a house viewed as a refuge, whose limits are fundamentally defined as mechanisms of exclusion and separation which maintains the order of what is habitual, to a house viewed as a set of limits that separate but also connect the habitual with otherness.

Security in home telecare does not mean the absence of uncertainty and therefore of danger. On the contrary, Security is a way of bringing uncertainty into the production of order. It is something that includes and addresses uncertainty, and which at the same times extends it productively.

This is the final proposition of this thesis and the sphere of research that I want to explore in the forthcoming years. In fact, I think that the main outcome of this thesis is having created the conditions for a research programme on the relationship between Security and care that includes a detailed analysis of how the security mechanisms are transforming the spaces of care, the lives that are cared for and the forms and practices of care-giving.

To conclude, I would like to go a little further into these three spheres of research and outline some of the contributions that can be made based on the study we conducted on the home telecare service, which I think will be interesting to further discuss and develop in the future.

\section{Security and spaces of care}

Unlike spaces of discipline, security operates not in places with defined limits but on surroundings or environments; in other words, on open, changing spaces. The installation of home telecare devices does not meaning laying down clear boundaries between a security perimeter and another unsafe area. The home space becomes redefined based on the multiple uses of the device. The goal is not to totally transform the home to adjust it perfectly to the functioning of the device, as some domotic home telecare projects aim to do, rather to set it up according to possible events. It is not necessary to make a self-contained world of the home or a care system.

In this sense, home telecare reveals a complete absence of utopia. There is no ideal house for home telecare because there is no pretension of perfection or harmony, rather the goal is to optimise the effects, reduce the negative aspects and maximise the positive side for a given situation. A norm devoid of morality is at play: executed simply as the effect of a positive and completely technical rationality that it tries to regulate from the real situation in itself.

Therefore, the characteristic of spaces of security such as home telecare is not they are extramural. What is truly important is that these spaces are shaped according to possible events and not so much on what ought to happen. In this sense, the space of home telecare is neither a network nor a place in itself; rather it is an environment or settings. The house and the community are environments but not places or networks. Unlike environments, both the place and the network appear as the result of an attempt at exclusion and indeterminateness. In both cases, what is important is the establishment of an order, on either an immobile or mobile environment. In this sense, places and networks are spaces of discipline. 
The environment, on the other hand, is a space laden with events and therefore modulated constantly by practices that try to incorporate them.

\section{Security and life}

The other aspect that home telecare highlights is that life is translated from the logic of accidents and danger. Security defines life according to its vulnerability. For example, HTC sets out from the idea that existence is not self-sustaining but that it depends entirely on social, economic and biological interactions that are never entirely assured. There are always dependencies that sustain the users' lives, dependencies with other people, with the space where one lives, with certain technical aids, with certain medicines and with certain routines. These dependencies are not a problem. There is no need to eliminate them. On the contrary, they should be assured because they are what ultimately give the users their autonomy. It is the inherent fragility of life that becomes a problem when we talk of vulnerability and seek greater security. In fact, it is precisely because vulnerability goes across all forms of life, HTC and other similar devices can be included in the everyday lives of all kinds of people, not just those who are dependent, disabled or ill. And in fact, that is what is happening. In this sense, HTC as a security device does not seek to enclose life within a category, but it nurtures its circulation and constant change. Basically, the goal is to modulate it according to the risks that arise, and for this reason the vulnerability or fragility of the dependencies that sustain our lives, is not something to avoid but a base on which to operate.

Managing life as something that is vulnerable means that the production of an identity that is perfectly adapted to the home telecare system is not completely necessary. The service does not seek to produce a specific kind of user. Home telecare as a security device is multifunctional; it does not aim to establish a use for each individual thing but to manage the different uses and the effects that each user might have. The goal is to adapt to the different habitual actions so that the combined effect is a greater sense of well-being. One example of this would be minimally changing daily routines and the domestic space to heighten the sense of control over one's own life and thus not aggravate problems associated with ageing, while also managing to maximise the chances of success of an urgent intervention by the telephone operators from the home telecare service. For this reason, there is no opposition or contradiction between the autonomous behaviour of users, viewed as constant supervision of a body-at-risk, and autonomy, viewed as the resistance of a vigorous body that denies its own weaknesses and handicaps. The security mechanism tries to accommodate both forms of autonomy in accordance with the effects that both have at different levels: health, welfare, monetary cost, technological use, etc.

\section{Security and Practices of Care}

The third aspect is directly related to care-giving practices. Safety in Latin is sine-cura (without care). When something is safe we can relax, be carefree. In this sense, any care-giving practice requires certain processes or elements to be assured. We cannot take care of everything. Caring, to the contrary, requires openness to the unexpected; sensitivity to imponderables, to what might happen; responsibility for whatever may happen.

According to these definitions, what is produced in the home telecare service is an assurance of the care in a twofold sense. First, through the use and development of systems of accountability and standardisation, the decisions become safer because they fit into a single pattern. The operators of the service, for example, 
know that if they follow the steps outlined in the protocols for each kind of call, the care they are going to provide will be useful and will help solve the problem as quickly as possible. However, as soon as they are applied, these standardised protocols cease to be numerous imponderables and specificities that do not fit. An essential part of the job performed in the service is precisely that of including these imponderables and these specificities in the service standards. Therefore, it is crucial to include the probable futures and their consequences in the care-giving practices. For this reason, protocol-based decisions are built based on a calculation of the risks that they entail, and in turn unforeseen consequences that must be included emerge constantly.

In this sense, assuring care is not simply imposing a series of accountability and auditing systems on the care-giving practices, as if it were a sort of technocratic colonisation. Instead, it is like the emergence of a carefully conceived security. Assuring care implies redefining the notion of security. This is precisely what we have aimed to stress in this study, and what I wish to examine further in the future. Remote home care teaches us that security does not necessarily have anything to do with a stable, constant, reliable order, with the production of places or networks of care where routine inscription technologies and totally regulated, standardised forms of care predominate. This security is careful, or it is a kind of assured care because the events turn into opportunities for setting new guidelines, new orders and new spatialities with which to set up life.

\section{Formato de citación}

López, Daniel (2009). Securizing care: Networks, Immediacy and Independence in a Home Telecare Service. Athenea Digital, 16, 185-193. Disponible en http://psicologiasocial.uab.es/athenea/index.php/atheneaDigital/article/view/684.

\begin{tabular}{l}
\hline Este texto está protegido por una licencia Creative Commons. \\
Usted es libre de copiar, distribuir y comunicar públicamente la obra bajo las siguientes condiciones: \\
Reconocimiento: Debe reconocer y citar al autor original. \\
No comercial. No puede utilizar esta obra para fines comerciales. \\
Sin obras derivadas. No se puede alterar, transformar, o generar una obra derivada a partir de esta obra. \\
$\underline{\text { Resumen de licencia }-\underline{\text { Texto completo de la licencia }}}$ \\
\end{tabular}

